DOI: $10.15503 /$ jecs20141-158-168

\title{
PSYCHOLOGICAL FACTORS OF THE IMAGE OF THE STATE IN THE STUDENTS' PERCEPTION
}

\author{
KARKOVSKA RUSLANA \\ Faculty of Philosophy, Ivan Franko National University, \\ Universytetska Str 1, Lviv, Ukraine \\ E-mail address: karkovska@inbox.ru

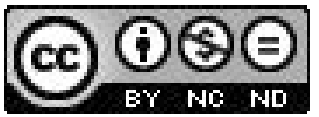

\begin{abstract}
The article is dedicated to the study of the psychological determination of the state's image in the students' perception. The results of empirical research of the influence of the students' adaptation and orientation to their vision of the state are described in the article. The state image in the perception of student youth was analyzed according to the parameters of the state's accomplishment assessment, the feeling of a sense of belonging to the state, the sense of vision of the state existence and the assessment of the state power as competent, effective, credible, and strong.
\end{abstract}

Key words: the image of the state, political socialization, political conception, students, individualistic orientation, adaptation, subjective prosperity, social frustration

\section{INTRODUCTION}

The research of political consciousness of student youth helps us to understand the deep sense of the social and political processes and predict the future transformations of the political system. The students of the institutions of higher education will form the layer of the citizens with high social status, and their political activity and behavior will determine the further development of the society. History has witnessed repeatedly, that the students may influence the urgent social and political situation, demonstrating a high level of political activity.

The image of the state is an important component in political consciousness of the citizens, in particular, of student youth. This image itself is a factor and, simultaneously, an indicator of the social position of a personality, which is displayed in the attitude of a personality to the social milieu not only within the framework of political interaction, but also in other spheres of life.

The analysis of the different authors' approaches (Khazratova, 2004, pp. 3- 13; Horbanyuk, Bilonos, Aksionova 2010, pp. 37 - 48; Shestopal, 2002, pp. 31 - 52; Drozdov, 2011, pp. 149 - 156; Fedyakin, 2005, pp. 179 - 190) to the state image interpretation allowed determining it as the political concept of a personality about the state as the social and political institution (its organizational structure, political authority, laws, etc.), his/her place as a citizen in the state and the inte- 
raction with the state and the other citizens. This is the result of psychological reflection of the social and political reality in consequence of the direct interaction with the representatives of the bodies of state authority and the other agents of political socialization, the perception of different spheres of their life and the indirect influence of the mass media.

The object of our empirical research was to reveal the psychological characteristics of students which influence their state image creation.

The theoretical basis of the research was the Nihora Khazratova's conception of the deep state image constructs and the approaches of Vadym Vasyutynsky and Olena Shestopal to the research of the political power concepts (Vasyutynskyi, 2005, pp. 411 - 437; Khazratova, 2004, pp. 3 - 13; Shestopal, 2002, pp. 31 - 52).

N. Khazratova distinguished deep individual constructs in the state image as: "I - anti I", "Harmony - Disharmony", "Sense - Nonsense". The last construct is the most important, because quite often the personality should interpret and estimate the state without the possibility of being aware of the actual condition in the state. Therefore the possibility to find sense in its existence is becoming highly important (Khazratova, 2001, pp. 26 - 36). "For the successful state functioning it is necessary to have a particular degree of citizens' identification with it: this enables it to reach consensus of the state and citizens' interests, ensures individual involvement of the citizens in the important country processes" (Khazratova, 1997, p. 69). N. V. Khazartova uncovered the specifics of deep constructs, which include the state image by means of the determination of their individual needs. The author considers that "the perceptible characteristics of the organization are fixed while its perception, depending on their meaningfulness in the satisfaction of definite social and psychological needs. The extent of its representativeness in the state image depends on it" (Khazratova, 2004, p. 5).

On the basis of V. Vasyutynskyi's (Vasyutynskyi, 2005, p. 430) and O. Shestopal's (Shestopal, 2002, pp. 31 -52) approaches to the study of the political authority conception we distinguished the parameters on the basis of which the students were proposed to estimate the state authority: strength, credibility, effectiveness and competence.

\section{THE INVESTIGATION PROCEDURE}

In order to reveal the psychological factors of the image of the state in the students' perception the following techniques were applied: the questionnaire of Ruslana Karkovska "The state image", the methodology "The research of individuals' perception of a group" (Moseyko, \& Nelisova, 1982, pp. 140-144), the individual multilevel questionnaire "Adaptability" of Alexei Maklakov and Sergey Chermyanin (Maklakov, \& Chermyanin, 2006, pp. 549-558), the scale of subjective prosperity (Anne Perrudet-Badoux, Gerald Mendelsohn, Jean Chiche; Mariya Socolova's adaptation) (Perrudet-Badoux, Mendelsohn, \& Chiche, 1988, pp. 121134) Mariya Sokolova's adaptation (Sokolova, 1996, pp. 1-17), and the methods of the diagnostics of the social frustration level of Ludvig Vaserman (modification of Victor Boyko) (Boyko, 2006, pp. 157-160). 
The author's questionnaire consists of 18 closed questions. It is proposed to answer the questions using the bipolar scale (two contrary answers are located on the poles), choosing the figure from 0 to 10 , which reflects their views the most accurately. The aim of the questionnaire is to study how deeply the students identify themselves with the state; to display their assessment of the state orderliness; to clarify whether the students find sense in the state existence or not. The students were also proposed to estimate the political authority according to the following parameters: strong, credible, competent and effective.

The study involved 93 individuals, in particular first to fifth year students of Ivan Franko National University of Lviv, between the ages of 16 and 22 years. The studied group contained 28 males and 65 females. Among them there were the students of the faculties of applied mathematics and informatics, philosophy, biology and journalism.

The empirical material was elaborated with the help of the methods of parametric and nonparametric statistics, as the normally distributed parameters were only those indices, which were studied through the tests and answers to 6 questions of the questionnaire.

The investigation was conducted in September - October 2013 before the mass political protest actions in Ukraine, which started in November 2013.

\section{THE RESULTS OF THE RESEARCH}

On the basis of the results of the descriptive statistics we can characterize the conception of the students under study about the state. The answers of the respondents to the question, whether they might go abroad to any western country as a permanent place of residence, were distributed in a range from 0 (no, under no circumstances) to 10 (yes, I would use any opportunity). The average point achieved is 5.13. $50 \%$ of answers are located in a range from 3 to 8 points. $25 \%$ of students declared their willingness to go abroad as a permanent place of residence (8-10 points).

The majority of the surveyed students are tolerant to people who went abroad for permanent residence. $25 \%$ chose the far pole (I understand them, everyone is looking for better conditions) on the bipolar scale, which reflects the responses. The answers of a half of the respondents are in the range from 5 to 9 points. Only $25 \%$ of the respondents chose $1-5$ points on the scale that means that they are prone to think that people who went abroad are betrayers of the country.

Assessing the measures of responsibility for the events in the state, the brightest was the students' inclination to consider that each citizen is responsible for the events in the state: half of the respondents assessed the measure of responsibility of each citizen in 10 points. The students make military $(\mathrm{Mo}=2$ at frequency $16 \%$ of the responses in the range from 2 to 7 points) and intelligentsia ( $\mathrm{Mo}=5$ at frequency $19.5 \%$ of the responses in the range from 4 to 8 points) the least responsible for the events in the state. The respondents assessed quite high the measure of responsibility of the President and politicians for the events in the state (50\% of marks are from 6 to 9 points).

The studied students declared a high level of emotional involvement in political events. Responding the question, whether they feel any emotions when hear 
about the political events in Ukraine in the news or from their friends, the respondents could choose the point on the scale from 0 (no, it does not evoke any my emotions) to 10 (yes, it often evokes my strong emotions). $50 \%$ of responses are in the range from 5 to 9 points. $25 \%$ evaluated the intensity of emotional experience, evoked by the events in the state from 9 to 10 points.

The respondents displayed the average level of tolerance to illegal actions of citizens, which are not directed against some particular people, but can have socially negative consequences (evasion from the paying taxes, illegal commerce, etc.). The answers to the questions about the attitude to people and their activities, that don't cause harm to particular people, but violate the law, were placed on the bipolar scale from 0 (I consider they are criminals) to 10 (I understand them rather well, it is impossible to do differently in our conditions). The empirical indices within this variable quantity are normally divided. The average point in the group is 4.53 , the bottom quartile is 3 points and the top quartile is 6 points.

We received the low evaluation of the contribution of the Ukrainian state to the society development: $50 \%$ of respondents assessed such contribution from 3 to 6 points $(\mathrm{Mo}=3$ at frequency 23). 62 personalities $(66.7 \%)$ evaluated the contribution of the Ukrainian state to the society development from 0 to 3 points inclusively.

The students estimated the conditions created by the state (Ukraine) in the context of its assistance in achievement of objectives below the average. $50 \%$ of the studied students marked from 3 to 5 on the scale where 0 meant "the conditions created by the state interfere with your achievement of objectives", and 10 meant "the conditions created by the state assist your achievement of objectives".

According to the respondents, they don't feel very safe living in Ukraine. The answers to this question were normally divided. The average point that indicates the level of personal protection constitutes $3.47 .50 \%$ of marks are in the range from 2 to 5 on the ten-point scale and it gives reasons to characterize the subjective valuation of the students' protection as below the average.

Responding the question, whether they feel that the political events and processes that take place in Ukraine concern them, $50 \%$ of the respondents chose the points from 5 to 8 (on the scale from 0 to10).

The valuation of students' personal possibilities to assist the state development is characterized as above the average. Between the poles from 0 - I don't feel that I can influence the development of the state, to 10 - I feel that I can assist the development of the state, $25 \%$ chose points from 0 to 4 points; $50 \%$ - from 4 to 8 points, $25 \%$ - from 8 to 10 points ( $\mathrm{Mo}=5$ at frequency 29 or $31 \%)$.

The majority of students consider that "whatever the state is, it is necessary for the organization of the society". $86 \%$ of the studied group assessed consent to the statement from 5 to 10 points on the ten-point scale. More than $25 \%$ of the respondents put 10 points $(\mathrm{Me}=8, \mathrm{Mo}=10$ at frequency 28$)$.

$25 \%$ of the students totally disagree with this statement that any state is an obstacle to the development of the society and each person, imposing restrictions. The majority of the students under investigation are not inclined to agree with this thought: $50 \%$ of the respondents chose from 1 to 4 points. 
The students are not inclined to consider that Ukrainian state is an ordered structure, where strict rules are applied. Half of people estimated their consent to this statement from 2 to 4 points.

6.25 is an average point (the answers are normally divided), according to which the students estimated the correspondence of their personal views to the statement that there is no order, but total disorder everywhere in Ukraine. The bottom quartile is 5 and the top quartile is 8 points.

The similar distribution of marks was obtained in the statement "There is a chaos in Ukraine": $50 \%$ evaluated their consent to this idea from 3 to 8 points. $\mathrm{Me}=6, \mathrm{Mo}=7$ at frequency $15.25 \%$ of the respondents marked 8-10 points on the scale that affirms that they share the opinion that there is chaos in Ukraine.

Most students under study consider that the situation in Ukraine is quite understandable. In the evaluation of the consent to the statement that the functioning of the state is too complex and bulky to understand, the bottom quartile is 1 , the top quartile is 5 , and $\mathrm{Mo}=3$ at frequency $18.25 \%$ of the students virtually did not agree with the statement (0-1 points).

Most of the students, comparing to the points of the last statement, consider that it is impossible to understand the situation in the state. In the assessment of the consent to the statement, the bottom quartile is 2, the top quartile is 7 , and $\mathrm{Mo}=4$ at frequency $13.25 \%$ of the students de facto did not agree with the statement (0-2 points).

The state authority received low marks from the students. In the evaluation of the marks according to four proposed parameters we can observe the shift to the left. On the left edge of the continuum were the following characteristics: weak, is not credible, incompetent, ineffective. The highest marks the state received for the parameter of strength (the top quartile is 2 , the bottom quartile is 5 , and $\mathrm{Mo}=4$ at frequency 20). The distribution of the students' marks of the state authority is shown in Figure 1.

The evaluations of the state authority of a half of the respondents are in the following range according to: strength - from 2 to 5 ; trust - from 1 to 4 ; competence - from 1 to 5 ; effectiveness - from 1 to 4 .

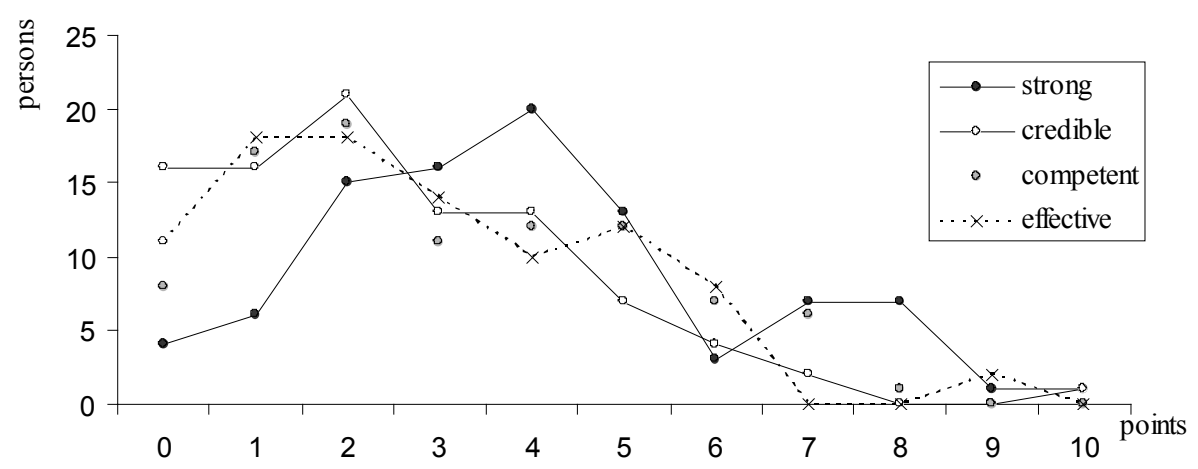

Fig 1. Students' evaluation of the state authority. Source: Authors`research. 
Consequently, the students assess the state authority quite low (the highest marks are received for the strength), declare their emotional indifference to the events in the country, and believe that each citizen is responsible for it. Though major students don't feel themselves protected in Ukraine, they consider that the Ukrainian government does not contribute to the development of the society and achievement of their objectives. Although the level of students who believe that they can influence the development of the state is above the average, but the major part of the students declared their willingness to go abroad to any western country for permanent residence, considering that there is total disorder in Ukraine.

Using Spearman's rank correlation we established connections between the parameters of the state image and psychological characteristics of the students.

We established the connection of the state image and social frustration of the students. The higher the students' social frustration level is:

- the less they are inclined to believe that Ukrainian state as a social institution contributes to the society development $(r=-0.4 ; p \leq 0.01)$;

- the more they agree with the statement that there is no order, but disorder in Ukraine ( $r=0.34 ; p \leq 0.01)$, chaos in Ukraine ( $r=0.34 ; p \leq 0.01)$;

- the less protected they feel $(r=-0.45 ; \mathrm{p} \leq 0.01)$;

- the more they are inclined to deny that the conditions created by the government contribute to achievement of their objectives $(r=-0.43 ; p \leq 0.01)$.

Thus, the assumption that the social frustration is a factor of negative state image in the students' perception was confirmed. It prevents formation of identity with the state and forms the conception of the state as a chaotic unregulated mass.

The students who consider that there is no order, but a mess in Ukraine are not satisfied with the situation in society $(\mathrm{r}=0.31 ; \mathrm{p} \leq 0.01)$ and are prone to mood changes $(\mathrm{r}=0.27 ; \mathrm{p} \leq 0.01)$.

It was found that the tendency to feel unprotected living in Ukraine is not only directly connected with the social frustration level, but it is also reversely correlated with the level of subjective prosperity $(\mathrm{r}=-0.3 ; \mathrm{p} \leq 0.01)$ and neuropsychic resistance $(\mathrm{r}=-0.28 ; \mathrm{p} \leq 0.01)$.

In the group of the surveyed students we observe the direct connection among the inclination to feel individual participation in the Ukrainian development, ability to contribute to it and subjective prosperity $(r=-0.29 ; \mathrm{p} \leq 0.01)$, adaptability ( $\mathrm{r}$ $=-0.3 ; \mathrm{p} \leq 0.01)$, neuropsychic resistance $(\mathrm{r}=-0.28 ; \mathrm{p} \leq 0.01)$ and communicative potential $(r=-0.28 ; p \leq 0.01)$. Negative coefficients of correlation are interpreted as a direct connection, because high points, according to the indicated scales, mean a low level of the characteristics, which they denote.

Consequently, adaptability to the social environment (adaptive abilities and subjective prosperity as an indicator of adaptability) is a factor in the formation of the involvement feeling of the student youth to the state.

According to the correlation analysis results it was revealed that students are prone to consider that the conditions created by the government are an obstacle for the achievement of their individual objectives, are characterized by the developed individualism $(\mathrm{r}=-0.29 ; \mathrm{p} \leq 0.01)$ and weakly expressed collectivistic orientation $(r=0.33 ; p \leq 0.01)$. If a person is prone to evade from collective forms of activity, 
prefers individual work, and a group itself is not an individual value for him/her, then this person will oppose himself/herself (at least in the form of passivity, not necessarily in active actions) to not only small social group, but also to big groups and the state, the institute which is ideally determined to organize and control different spheres for creation the optimal conditions for citizens coexistence.

With the help of factorial analysis the normally divided empirical data, the pentad model, which examines $70 \%$ of scattered data, was received. For our investigation the first and the second are the factors of interest.

The first factor is "low adaptability" (M1 emp. $=0.97)$ includes adaptive abilities (moral standards (M1 emp. $=0.54)$, neuropsychic resistance $(\mathrm{M} 1 \mathrm{emp} .=0.9)$, communicative potential $(\mathrm{M} 1 \mathrm{emp} .=0.77)$, social frustration $(\mathrm{M} 1 \mathrm{emp} .=0.6)$ and subjective trouble $(\mathrm{M} 1 \mathrm{emp} .=0.81)$.

The second factor is "defencelessness in the state with the disorder", which combined the conception of the students about the state:

- the desire to go abroad for the permanent place of residence (M1 emp. $=0.56$ );

- prone to think that there is no order in Ukraine, but total disorder (M1 emp. $=0.58$ );

- prone to share the idea that it is impossible to understand what is going on in Ukraine (M1 emp. = 0.59);

- the feeling of defencelessness in their own country (Ukraine) (M1 emp. $=-0.81$ ).

Within the second factor we can observe distinctly expressed social frustration (M1 emp. $=0.43)$.

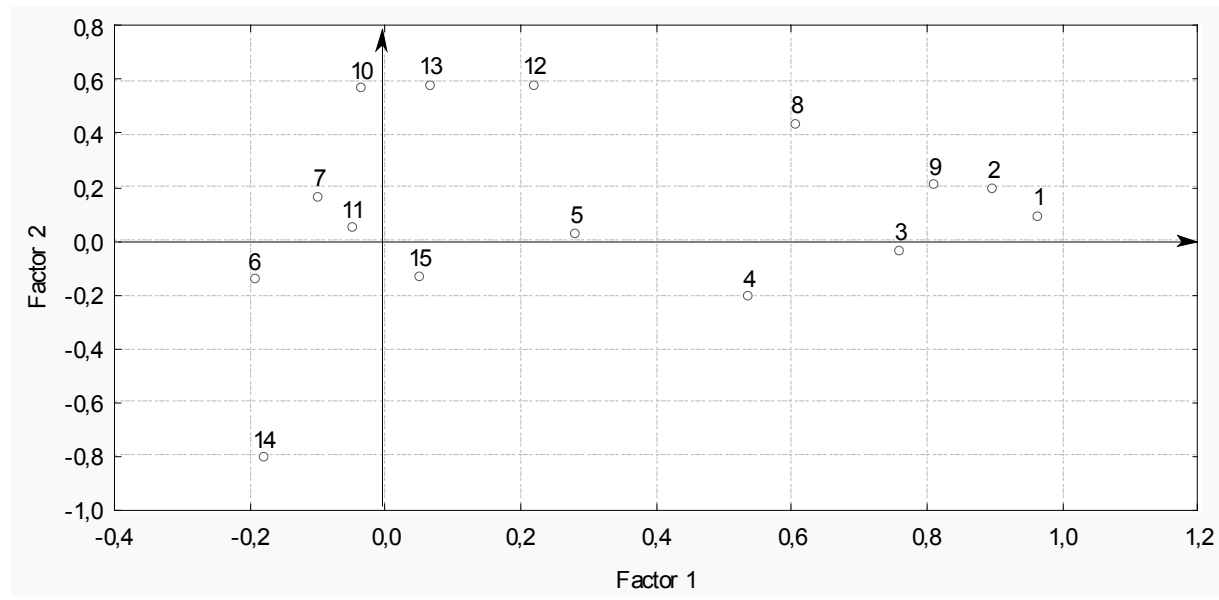

Fig. 2. Variables in the plane of the $1^{\text {st }}$ and $2^{\text {nd }}$ factors.

1 - adaptability (low), 2 - neuropsychic instability, 3 - communicative potential (low), 4 - moral normative(less) value, 5 - individualistic orientation, 6 - collectivistic orientation, 7 - pragmatic orientation, 8 - social frustration, 9 - subjective trouble, 10 - desire to go abroad for the permanent place of residence, 11 - toleration of illegal actions (nonpayment of taxes, illegal business), 12 - prone to consider that there is no order in Ukraine, but total disorder, 13 - prone to think that it is impossible to understand what is going on in Ukraine, 14 - the feeling of protection, living in Ukraine, 15 - the evaluation of effectiveness of the state authority in Ukraine.

Source: Authors`research. 
The analysis of variables in the plane of the $1^{\text {st }}$ and $2^{\text {nd }}$ factors proved that social frustration is clearly expressed in both factors. Thus, we can draw a conclusion that a personality with low adaptability will be prone to low subjective prosperity, social frustration and the feeling of defencelessness in the state, which he/she will perceive as unregulated. Social frustration depends on both adaptation ability of a person and the subjective characteristics of social milieu, in which he/she dwells. The more favorable conditions and the higher social guarantees are, the less social frustration of a personality will be. The negative state image is a result of personality's dissatisfaction with different social spheres.

With the help of cluster analysis (the method of tree clustering) of empirical data (the indices of adaptive abilities, orientations, social frustration and subjective prosperity) three clusters were distinguished (table 1).

Tab. 1. The mean values of indices of psychological characteristics in three clusters.

\begin{tabular}{|l|c|c|c|}
\hline \multirow{2}{*}{$\begin{array}{c}\text { Psychological characteristics of } \\
\text { the students }\end{array}$} & \multicolumn{3}{|c|}{ The mean values } \\
\cline { 2 - 4 } & $\begin{array}{c}\text { Cluster 1 } \\
\text { 29 students }\end{array}$ & $\begin{array}{c}\text { Cluster 2 } \\
\text { 31 students }\end{array}$ & $\begin{array}{c}\text { Cluster 3 } \\
\text { 33 students }\end{array}$ \\
\hline adaptability (low) & 67.88 & 83.36 & 47.14 \\
\hline neuropsychic instability & 41.12 & 50.92 & 27.11 \\
\hline communicative potential (low) & 15.45 & 20.28 & 11.31 \\
\hline moral normative(less) value & 11.30 & 12.16 & 8.71 \\
\hline individualistic orientation & 4.36 & 6.72 & 4.43 \\
\hline collectivistic orientation & 6.39 & 3.52 & 6.26 \\
\hline pragmatic orientation & 3.24 & 3.76 & 3.31 \\
\hline social frustration & 1.52 & 1.89 & 1.23 \\
\hline subjective trouble & 5.30 & 6.72 & 3.43 \\
\hline
\end{tabular}

Source: Authors`research.

The comparison of the mean values of psychological qualities of three studied clusters on the basis of Henry Scheffe criterion (Babenko, 2009, pp. 109-112), gave us an opportunity to reveal students' characteristics, which formed the clusters. There is no distinction between three clusters only on the level of pragmatic orientation, but the clusters differ significantly according to the other characteristics.

The second cluster differs from two others by having the lowest indices of adaptive abilities (the highest indices of neuropsychic instability, low communicative potential). The students that belong to the second cluster are characterized by the highest individualistic orientation (and the lowest collectivistic orientation), the highest level of frustration and indices of subjective trouble.

Among the investigated first and second clusters no essential differences according to the orientation were found (in both clusters collective orientation, comparing to individualistic, prevails). Though, the third cluster is characterized by higher (and the highest among all) subjective prosperity than the first, the lower level of social frustration and the highest indices of adaptive ability.

Thus, the students with the characteristic of collectivistic orientation have higher indices of adaptability than individualistic students. The collectivistic stu- 
dents value the interaction with social milieu and don't withdraw themselves from the group, which is a value for them. However they divided into two groups, which are unlike according to the levels of subjective prosperity and social frustration. In the group of students with collectivistic orientation who have the higher level of subjective prosperity and the lower level of social frustration, the higher abilities of adaptability are observed (in particular, the highest level of moral normative value). It is worth mentioning that the level of moral normative value in the group of collectivists with the lower indices of adaptability does not distinguish from the indices of the same scale in the group of individualistic students, who demonstrated the lowest level of adaptability among the respondents.

According to the William H. Kruskal - Wallis criterion (Babenko, 2009, pp. 101-103) there were noticed significant distinctions among the state conception of the studied students that belong to different clusters. The most prone to share the idea that the Ukrainian state as a social institution assists the development of the society and citizens, are the students that belong to the second cluster $(\mathrm{Me} 3=$ $5)$; the less prone to think so are the students of the second cluster $(\mathrm{Me} 2=3)(\mathrm{H}=$ $8.56, \mathrm{p}=0.0138$ ).

The studied people of the second cluster demonstrated the highest disposition to share the idea that there is no order in Ukraine, but total disorder (Me2 $=8 ; 50 \%$ of the cluster estimated the consent with the statement from 6 to 9 points). The less prone to consider that there is no order in Ukraine, but disorder are the members of the third cluster $(\mathrm{Me} 3=6,50 \%$ of the cluster estimated the consent with the statement from 3 to 7 points) ( $\mathrm{H}=7.66, \mathrm{p}=0.02)$.

Similar are the results of the comparison of clusters about the Ukrainian state as a state in chaos: the less prone to observe the chaos in Ukraine, are the members of the third cluster $(\mathrm{Me} 1=6, \mathrm{Me} 2=7, \mathrm{Me} 3=5, \mathrm{H}=9.24, \mathrm{p}=0.01)$.

The third cluster students declared the highest points of the feeling of protection (responses to the question of the questionnaire: Do you feel yourself protected, living in Ukraine?). 50\% of the third cluster respondents estimated their protection from 3 to 7 points. The personal protection of a half of the second cluster was evaluated from 0 to 4 points; and the first - from 2 to 5 points.

The students that constitute the third cluster, more than other students under study feel that the development of Ukraine depends on them personally and feel the ability to join the social progress. The lowest points for this question were received from the respondents of the second cluster $(\mathrm{Me} 1=6, \mathrm{Me} 2=4, \mathrm{Me}=7$; $\mathrm{H}=8,8, \mathrm{p}=0.01$ ).

The students of the third cluster are more prone to consider that the conditions created by the state (Ukraine) facilitate the achievement of their objectives. The points obtained for this question in three clusters are the following:

1 cluster - 50\% of marks of the first cluster are in the range from 3 to 5 points, $25 \%$ - from 5 to 9 points, $25 \%$ - from 1 to 3 points;

2 cluster $-75 \%$ of marks of the second cluster are in the range from 2 to 5 points, $25 \%$ - from 0 to 2 points;

3 cluster - 50\% of marks of the third cluster are in the range from 4 to 6 points, $25 \%$ - from 6 to 9 points, $25 \%$ - from 1 to 4 points (Figure 3). 


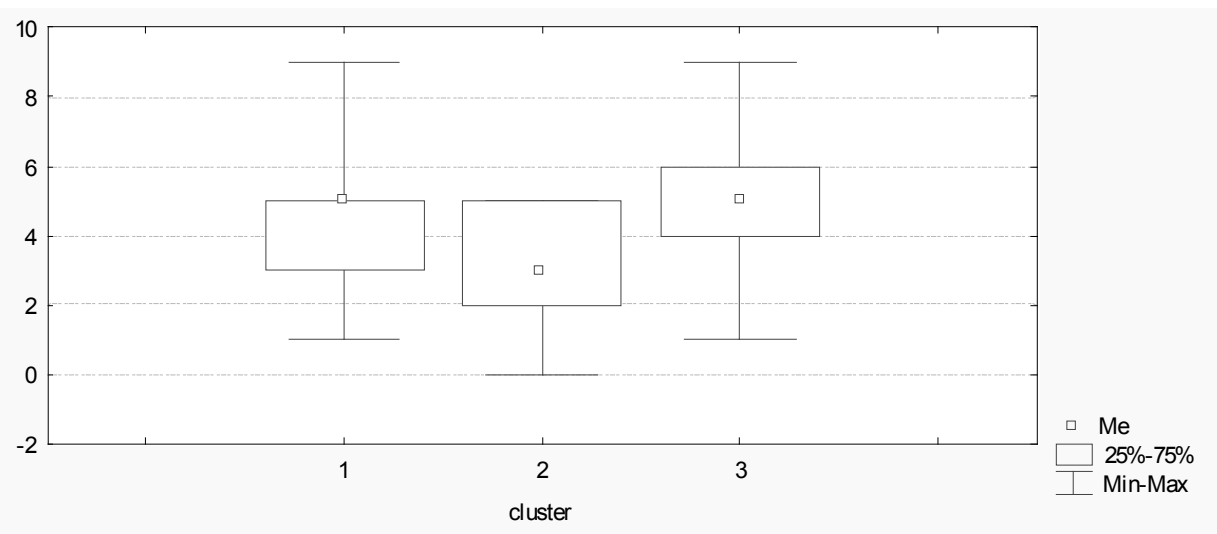

Fig. 3. The distribution of the answers of the students of three clusters to the question "Do the conditions created by the state facilitate the achievement of your objectives?"

Source: Authors`research.

Thus, the image of the state in the students' perception significantly depends on their orientation and adaptability. The students of collectivistic orientation with the highest level of adaptability demonstrated the highest level of the feeling of involvement with the state and its perception as an orderly system. However, the majority of the students find sense.

\section{CONCLUSIONS}

Thus, there is the direct connection between the inclination to feel personal involvement in the development of Ukraine and subjective prosperity, and adaptability of the students. The results obtained confirmed that adaptability (the satisfaction of the different life spheres, positive emotional condition and developed abilities to adapt) and collectivistic orientation of the students assist the development of their positive state image. In particular, they influence the formation of the feeling of the state involvement and treatment of the state as an orderly structure. It was revealed that the inclination to consider the conditions created by the state as an obstacle to the achievement of personal objectives is directly connected with collectivistic orientation of the students and reversely - with individualistic orientation.

It was established that the students of collectivistic orientation have higher indices of adaptability and more positive conception about the state, comparing to individualistic students. The students of collectivistic orientation and with the highest indices of adaptability among all the students under study are the most prone to consider that the Ukrainian state as a social institution assists the development of the society and citizens and the achievement of their objectives; there is order in Ukraine, not disorder. Those young people state that they feel protected, living in Ukraine, and consider that the development of the state depends on them personally, and they feel able to join the social progress. 


\section{REFERENCES}

Babenko B. (2009). Babenko B. Fundamentals of probability theory and statistical methods of data analysis in psychological and educational experiments. Lviv: Publishing House of Lviv Ivan Franko National University.

Boyko, V. (2006). The methods of the diagnostics of the social frustration level of L. Vaserman (modification). In: D. Raygorodskiy (Ed.), The practical psychodiagnosis. Methods and tests (pp. 157-160). Samara: Publishing House "Bahr M".

Fedyakin, A. (2005). The image of a government: theoretical and methodological aspects. Aspects, 3, 178-190.

Drozdov, O. (2011). The images of the state as a component of geopolitical consciousness. The herald of Chernihiv National Pedagogical University. Series: Psychological sciences, 94/1, 149-156.

Horbanyuk, O., Bilonos, V., \& Aksionova, Y. (2010). The image of Ukraine and the states of the former Soviet Union in the perception of the Poles. Social psychology, 2, 37- 48.

Khazratova, N. (2001). A structural model of the image of a state. Psychological perspectives, 1. 26-36.

Khazratova, N. (2004). A typological model of the individual psychological state image. Social psycho$\log y, 4,3-13$.

Khazratova, N. (1997). Problem of the unconscious in the personal attitude to the state. In: V. Vasyutynsky (Ed.), The psychology of mass political consciousness and behavior (pp. 67-81). Kyiv: "DOK-K".

Maklakov, A., \& Chermyanin, S (2006). The individual multilevel questionnaire "Adaptability. In: D. Raygorodskiy (Ed.), The practical psychodiagnosis. Methods and tests (pp. 549- 558). Samara: Publishing House "Bahr M".

Moseyko, E., \& Nelisova, I. (1982). The research of individuals' perception of a group. In: H. Kitajgorodskaja (Ed.), Revitalization of the training activities (pp. 140-144). Moscow, Moscow State University.

Shestopal, E. (2002). The Russian images of a state in the end of XX century. Some results of the investigation of 1993-2002. In: E. Shestopal (Ed.), The psychology of the power perception (pp. 31-52). Moscow: Social and political thought.

Sokolova, M. (1996). The scale of subjective well-being. Yaroslavl: Psychognosis.

Perrudet-Badoux, A., Mendelsohn, \& G., Chiche, J. (1988). Développement et validation dune échelle pour Vévaluation subjective du bien-être [Development and Validation Scale of Subjective WellBeing]. Cak Antkropol Biomet Hum, 3, 121-134.

Vasyutynsky, V. (2005). Interactional psychology of a power. Kyiv: Kyiv Slavonic University. 